\title{
A fly by any other name
}

\section{Drosophila experts argue over reclassification proposal.}

The Byzantine world of species taxonomy is facing a new test: a proposal that would involve renaming Drosophila flies, arguably the leading model genetic organism.

The idea is to bring a new taxonomic order to the more than 2,000 species now grouped in the genus Drosophila. An application pending before the International Commission on Zoological Nomenclature (ICZN) would designate Drosophila melanogaster - the primary species used for genetics studies - as the type species for the genus. Currently, the type species is D. funebris, which was described in 1787 by Johann Fabricius.

Kim van der Linde, a postdoctoral researcher at Florida State University in Tallahassee, and colleagues filed the application in December 2007. Recent genetic work has shown that D. melanogaster could be classified as Sophophora and could therefore be renamed Sophophora melanogaster. Van der Linde says her proposal is designed to preserve the name D. melanogaster.

Launching the idea to update the nomenclature has let the fly-naming conundrum out of the bottle, touching off what ICZN staff call an unprecedented debate. Some worry that teaching, citation searches, publications and databases such as FlyBase would face a logistical nightmare if $D$. melanogaster changed its name.

"If this were some obscure beetle, you could rename it Godzilla and it wouldn't make much difference," says Therese Markow, a geneticist at the University of California at San Diego who directs the Drosophila Species Stock Center. "But this is the premier genetic model system." In November 2008, Markow convened a workshop in San Diego where many of the world's leading Drosophila authorities wrestled with van der Linde's proposal, without resolve.

Markow supports the status quo. So does Thomas Kaufman, a Drosophila geneticist at Indiana University in Bloomington and coleader of FlyBase. "We should leave the naming alone - everything is working fine," he says. "We can't even get agreement on names for the mutants, let alone the whole genus." A number of formal comments on the ICZN petition were strongly opposed to it.

Still, some taxonomists say it's time for reordering, especially given the recent sequencing of many Drosophila species, such as the 2007 publi-

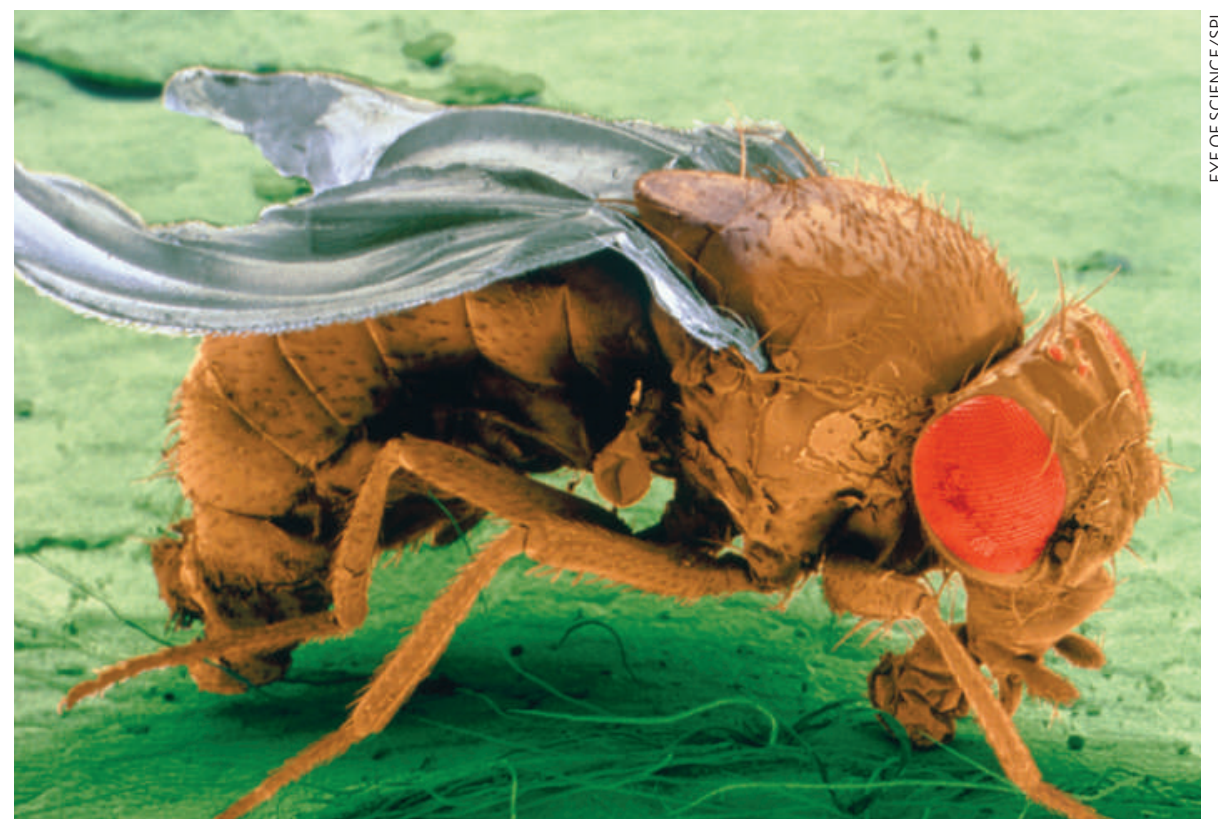

Name game: Should the Drosophila melanogaster fly be the type species for the genus?

cation of a dozen genomes that show how closely related species are to each other on a genetic level ${ }^{1,2}$. Van der Linde, a community ecologist trained in the Netherlands, got started on her proposal after doing some fieldwork in the Philippines. She joined up with several colleagues, including the Drosophila taxonomist Masanori Toda of Hokkaido University in Japan, and naming authority Gerhard Bächli of the Zoological Museum in Zurich, Switzerland.

The group developed a petition (see http://tinyurl. com/999mep) for the ICZN, and wrote a manuscript prescribing their interpretation. In renaming, a scientist can seek the approval of the commission, which then publishes the decision of its panel of about 25 authorities. Or a scientist can publish an article proposing the new order, leaving it to scientific communities to adjust names. "People can follow or reject us," says van der Linde.

A decision from the commission could take another year or more. If it rejects the proposal, taxonomists could take it on themselves to split the genera in descriptions in future publications. Under this scenario, D. melanogaster could become S. melanogaster, and 1,000 other species could be renamed too.
Earlier this month, van der Linde said she received commission feedback suggesting the petition may be set aside. That would leave the community to split the genus at will. This approach is supported by the international editorial team of the BioSystematic Database of World Diptera, a US-based fly name resource. In a comment on van der Linde's petition, they note that today's computer search engines "will have no trouble finding information" if D. melanogaster were to become $S$. melanogaster.

Patrick O'Grady, a geneticist at the University of California at Berkeley who does not support the van der Linde proposal, disagrees. "There would be chaos in the literature if D. melanogaster changes to S. melanogaster," he says. "Genetic work could be lost. It would be hard to find things." As an example, he points to the 2004 renaming, through publication ${ }^{3}$, of the mosquito that spreads yellow fever and dengue: Aedes aegypti to Stegomyia aegypti. Some researchers cite the new name; others ignore it and use the old name ${ }^{4}$.

\section{Rex Dalton}

1. Stark, A. et al. Nature 450, 219-232 (2007).

2. Markow, T. A. \& O'Grady, P. M. Genetics 177, 1269-1276 (2007).

3. Reinert, J. F., Harbach, R. E. \& Kitching, I. J. Zool. J. Linn. Soc. 142, 289-368 (2004).

4. Polaszek, A. Trends Parasitol. 22, 8-9 (2006). 